\title{
In Situ Neutron Diffraction Characterization of Phases in Co-Re-Based Alloys at High Temperatures
}

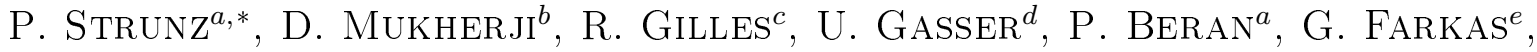 \\ M. HOFMANN ${ }^{c}$, L. KARGE ${ }^{c}$ AND J. RÖSLER ${ }^{b}$ \\ ${ }^{a}$ Nuclear Physics Institute ASCR, Rež near Prague, CZ-25068, Czech Republic \\ ${ }^{b}$ TU Braunschweig, Institut für Werkstoffe, Braunschweig, Germany \\ ${ }^{c}$ TU München, Forschungs Neutronenquelle Heinz Maier-Leibnitz, Garching, Germany \\ ${ }^{d}$ Laboratory for Neutron Scattering, PSI, Villigen, Switzerland \\ ${ }^{e}$ Charles University in Prague, Department of Physics of Materials, Prague, Czech Republic
}

\begin{abstract}
Co-Re-based alloys strengthened by carbides are promising candidates for new high-temperature alloys for gas turbine applications. The high temperature microstructure and its stability are of utmost importance, e.g. due to strengthening-phase selection. Neutron scattering, providing in situ information at high temperatures, was extensively used in the past for the Co-Re alloys research. The paper focuses on TaC strengthened alloy, particularly on the stability $\mathrm{TaC}$ precipitates which were previously shown not to dissolve up to at least $1300^{\circ} \mathrm{C}$. Small-angle neutron scattering shows that its finer morphological variant - most suitable for high temperature strengthening - coarsened even at relatively low temperature of $1000{ }^{\circ} \mathrm{C}$. This coarsening is faster at higher temperatures and the mean size exceeded $1000 \AA$ (i.e. the size — detection limit of the used facility) after $4 \mathrm{~h}$ hold at $1200^{\circ} \mathrm{C}$
\end{abstract}

DOI: 10.12693 /APhysPolA.128.684

PACS: 61.05.fg, 61.66.Dk

\section{Introduction}

In the development of new high-temperature alloys for gas turbine applications, various candidates are under consideration. Co-Re-based alloys [1] strengthened by carbides, or eventually by $\mathrm{Cr}_{2} \mathrm{Re}_{3}$ type $\sigma$ phase, is one promising option. They are being developed to supplement the Ni-base superalloys used in gas turbine applications at very high temperatures $\left(\geq 1473 \mathrm{~K}\left[1200^{\circ} \mathrm{C}\right]\right.$ bare metal temperature). Unlike other commercial Cobased alloys, the Co matrix in Co-Re alloys has a stable hexagonal close-packed (hcp, also denoted $\varepsilon$ ) structure at room temperature. Co-Re-based alloys are strengthened at high temperatures (HT) by precipitation of fine dispersion of minority phase. Therefore, the high temperature microstructure and its stability are of great importance for applications and deserve attention.

The microstructure of $\mathrm{Co}-\mathrm{Re}$ alloys is rather complex $[1,2]$. For example, it contains several morphological variants of $\mathrm{Cr}_{23} \mathrm{C}_{6}$ carbides in different size scale. One variant is the fine lamellar morphology (Fig. 1), which strengthens the alloy to temperatures up to $1000^{\circ} \mathrm{C}$.

Neutron scattering provides an excellent tool for studying structural and microstructural changes in materials in situ at high temperatures. Therefore, it is extensively used in the Co-Re alloy development for structural and microstructural characterization.

* corresponding author; e-mail: strunz@ujf.cas.cz

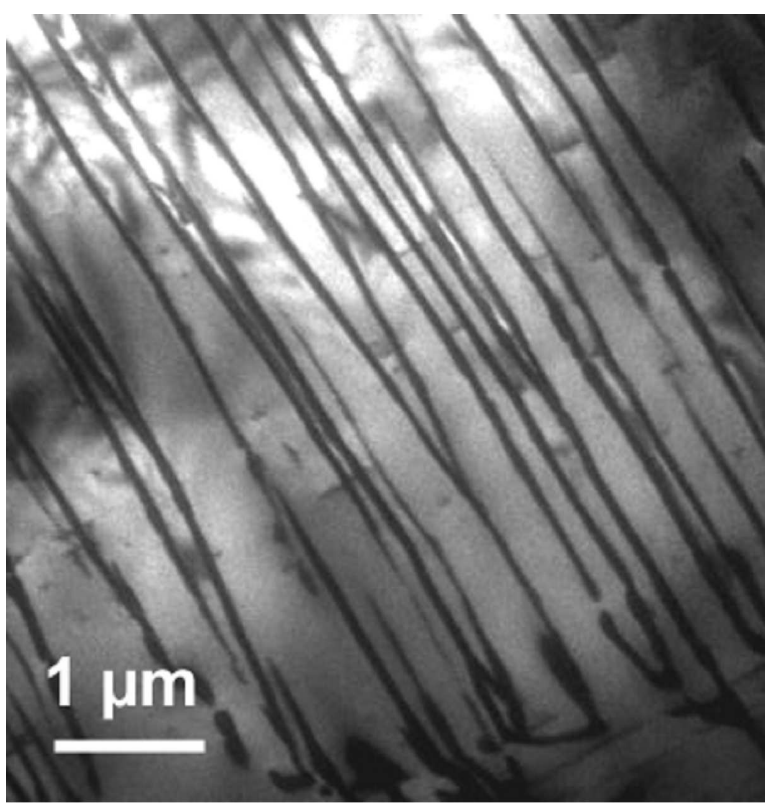

Fig. 1. Lamellar $\mathrm{Cr}_{23} \mathrm{C}_{6}$ type carbides in the $\mathrm{Co}-\mathrm{Re}$ alloy.

Using a high-temperature vacuum furnace, in situ neutron diffraction study on experimental Co-Re alloy hardened by $\mathrm{Cr}_{23} \mathrm{C}_{6}$ carbides (the experimental alloy denominated CoRe-1, composition $\mathrm{Co}-17 \mathrm{Re}-23 \mathrm{Cr}-2.6 \mathrm{C}$, in at.\%) showed that the matrix undergoes a hexagonal close packed to face-centered cubic (hcp $\leftrightarrow$ fcc) allotropic transformation when heating to high temperature (above 
$\left.1160{ }^{\circ} \mathrm{C}\right)$ [2]. Furthermore, it was found that this transformation has a large hysteresis $(\approx 100 \mathrm{~K})$ and, therefore, it takes place in a rather broad temperature range 1130 to $1260^{\circ} \mathrm{C}$.

It was also shown using neutron diffraction that the matrix transformation and hysteresis could be significantly influenced by element additions. In the ternary alloy $\mathrm{Co}-17 \mathrm{Re}-23 \mathrm{Cr}$ with $200 \mathrm{ppm}$ (weight) boron addition, which does not contain any carbides, the matrix phase transformation from hcp to fcc structure takes place in the temperature range from 1548 to $1673 \mathrm{~K}$ $\left(1275\right.$ to $\left.140^{\circ} \mathrm{C}\right)$ [3]. It means that the transformation is shifted to much higher temperature when compared to the CoRe-1 alloy and also the hysteresis is substantially narrower $(\approx 50 \mathrm{~K})$. Because any instability in the matrix during service of the $\mathrm{Co}-\mathrm{Re}$ alloys is undesirable, these observations are positive with respect to the hightemperature application of the $\mathrm{Co}-\mathrm{Re}$ alloys and give room for fine tuning of the alloy design. The boron addition also strongly influences the amount and stability of the $\sigma$ phase (which is another potential strengthening phase) in the alloy.

High-temperature cycling experiments up to $1300^{\circ} \mathrm{C}$ performed in situ on Co-Re alloys in parallel with neutron diffraction measurements (FRM II neutron source, Garching) described in detail not only the hcp $\leftrightarrow$ fcc phase transformation of the matrix [2], but also the evolution of minority phases during the repeated thermal cycles $[2,4,5]$. It was found that a candidate for strengthening - $\mathrm{Cr}_{23} \mathrm{C}_{6}$ carbides - dissolves during the hcp $\leftrightarrow$ fcc phase transformation above $1200^{\circ} \mathrm{C}$ in the CoRe- 1 alloy and re-appears only on cooling below $1140^{\circ} \mathrm{C}$ (following the hysteresis of the matrix). It was also observed by small-angle neutron scattering (SANS) [6] that $\mathrm{Cr}_{23} \mathrm{C}_{6}$ lamellae coarsen already at relatively low temperature of $1000{ }^{\circ} \mathrm{C} . \mathrm{Cr}_{23} \mathrm{C}_{6}$ carbides alone are thus not suitable for HT strengthening, despite their fine lamellar morphology.

Therefore, a new step in the alloy development was to add tantalum in order to produce $\mathrm{TaC}$ carbides. It is known that MC-type carbides are generally more stable than $\mathrm{M}_{23} \mathrm{C}_{6}$ carbides. The new alloy $(\mathrm{Co}-17 \mathrm{Re}-23 \mathrm{Cr}-$ 1.2Ta-2.6C) was designated CoRe-2. By means of a suitable heat treatment, very fine $(<300 \AA)$ TaC precipitates can be dispersed uniformly [7]. Such a microstructure is promising as it is ideal for providing creep resistance due to the interaction of the $\mathrm{TaC}$ precipitates with dislocations.

A complex microstructure develops in this Ta-carbide strengthened CoRe-2 alloy (see e.g. [4, 8]). Various morphological variants of $\mathrm{TaC}$ and $\mathrm{Cr}_{23} \mathrm{C}_{6}$ carbides as well as $\mathrm{Cr}_{2} \mathrm{Re}_{3}$-type $\sigma$ phase are present in the microstructure. In the standard heat treated CoRe-2 alloy, $\mathrm{Cr}_{23} \mathrm{C}_{6^{-}}$ type and $\mathrm{TaC}$ carbides are actually present in very different size scales - as large grain boundary or blocky carbides and as very fine lamellar or globular precipitates. Figure 2 shows the fine dispersion of $\mathrm{TaC}$ which is embedded in $\varepsilon$ Co matrix. In the CoRe-2 alloy, these precipitates appear between the $\mathrm{Cr}_{23} \mathrm{C}_{6}$ lamellae. The fine precipitates can provide the high temperature strengthening. Nevertheless, a long term stability of this microstructure at high temperatures is important for gas turbine applications and has to be examined.

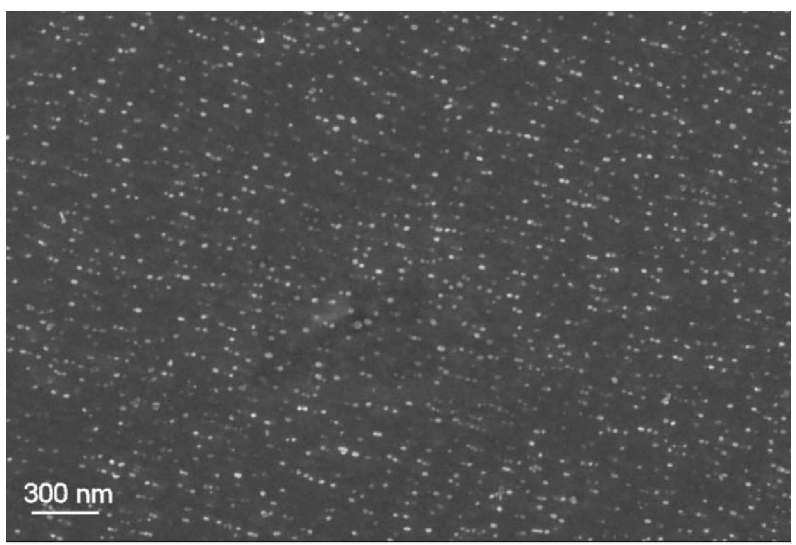

Fig. 2. SEM image of the CoRe-2 alloy sample: fine dispersion of $\mathrm{TaC}$ carbides.

Unlike $\mathrm{Cr}_{23} \mathrm{C}_{6}$ carbides and $\sigma$ phase, the $\mathrm{TaC}$ phase in the CoRe-2 alloy seems to be stable up to at least $1300^{\circ} \mathrm{C}$ as its volume fraction determined by in situ wide angle neutron diffraction did not change significantly during heating, and even the matrix transformation does not influence it $[2,4]$. It has to be, however, noted that several morphological variants of $\mathrm{TaC}$ are present in the alloy: fine globular particles seen in Fig. 2 (suitable for strengthening), large Chinese-script-like precipitates at and near grain boundaries and blocky carbides within grains. Wide angle neutron diffraction cannot distinguish these morphological variants clearly.

Investigation of possible coarsening of fine $\mathrm{TaC}$ carbides is a task for in situ SANS. During the first experiments focused on the TaC morphology and stability at HT [8], it was found that the SANS curves change during the hold at $1200^{\circ} \mathrm{C}$. The model composed of lamellar $\mathrm{Cr}_{23} \mathrm{C}_{6}$ carbides, spherical fine $\mathrm{TaC}$, and large particles giving asymptotic scattering was used for the evaluation. The results [8] indicated that the $\mathrm{TaC}$ carbides coarsen during the hold at $1200^{\circ} \mathrm{C}$.

In the present paper, it was tested using SANS [9] technique how the fine $\mathrm{TaC}$ precipitates in CoRe- 2 alloy evolve during the hold at various temperatures between 1000 and $1300^{\circ} \mathrm{C}$.

\section{Experimental}

Ta carbide strengthened CoRe-2 alloy (Co-17Re$23 \mathrm{Cr}-1.2 \mathrm{Ta}-2.6 \mathrm{C}$ ) was melted in a vacuum arc furnace and cast in solid $\mathrm{Cu}$ molds. The cast bars were homogenized under vacuum in three steps in the temperature range $1623-1723 \mathrm{~K}\left(1350-1540^{\circ} \mathrm{C}\right.$ ) for $15 \mathrm{~h}$ (referred to as ST heat treatment) to remove strong segregation of heavy elements in the cast structure. The samples of around $1 \mathrm{~mm}$ thickness were heated up to either 1000 
(sample denoted y), $1100(\mathrm{v}), 1200(\mathrm{w}), 1260(\mathrm{u})$, or $1300{ }^{\circ} \mathrm{C} \mathrm{(z)}$ and held for $4 \mathrm{~h}$ at the high temperature using special high-temperature vacuum furnace. During the hold, in situ SANS measurement was carried out. The pinhole SANS-II facility [10] at SINQ (PSI Villigen) was used for the measurement (some preliminary tests were also performed at NPL lab of CANAM, NPI Řě̌, Czech Republic [11]).

The scattering data were collected at several (reproducible) experimental geometries of the instrument during the hold at a particular temperature, i.e. the measurements at various geometries were done with the same sample. The data acquisition time for one SANS pattern (i.e. at a given geometry) was $10 \mathrm{~min}$, which enables to see possible microstructural change during the hold at a given temperature, which extended for $4 \mathrm{~h}$.

The sample-to-detector distance was varied from $1.2 \mathrm{~m}$ to $6 \mathrm{~m}$ and the neutron wavelengths $\lambda$ of $6.3 \AA$ and $10.5 \AA$ were used. The full covered range of scattering vector magnitude $Q\left(Q=|\boldsymbol{Q}|=\left|\boldsymbol{k}-\boldsymbol{k}_{0}\right|\right.$, where $\boldsymbol{k}_{0}$ and $\boldsymbol{k}$ are the wave vectors of the incident and of the scattered neutrons, respectively, and $\left.|\boldsymbol{k}|=\left|\boldsymbol{k}_{0}\right|=2 \pi / \lambda\right)$, was $5.0 \times 10^{-3} \AA^{-1}-0.125 \AA^{-1}$ (i.e. $5.0 \times 10^{-2} \mathrm{~nm}^{-1}<$ $\left.Q<1.25 \mathrm{~nm}^{-1}\right)$. The measured raw data were corrected for background scattering and calibrated to absolute scale using the measurement of the (attenuated) primary beam [12]. In this way, macroscopic differential cross-section $\mathrm{d} \Sigma / \mathrm{d} \Omega(Q)$ was obtained.

\section{Results and discussion}

A selected set of measured scattering curves is displayed in Fig. 3.

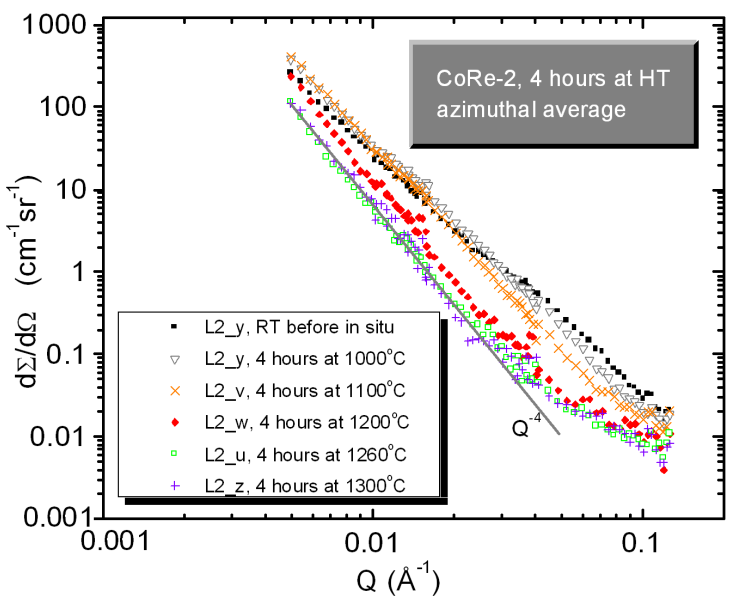

Fig. 3. Selected scattering curves: samples held for $4 \mathrm{~h}$ at HT.

It can be seen that relatively large scattering intensity exists at large $Q$-values for the ST sample measured at RT before in situ heating. It is the same result as the one already reported on a different CoRe-2 sample earlier [8]. The RT scattering data cannot be described adequately by only one log-normal size distribution of inhomogeneities. Altogether three components has to be considered: (i) fine globular $\mathrm{TaC}$ particles, (ii) fine lamellar $\mathrm{Cr}_{23} \mathrm{C}_{6}$ carbides, (iii) scattering from large particles (including $\sigma$ phase, large Chinese-script like $\mathrm{TaC}$ and large $\mathrm{Cr}_{23} \mathrm{C}_{6}$ carbides which are over the size-detection limit of the used SANS facility) giving Porod-law scattering $\left(Q^{-4}\right.$ dependence). Constant incoherent background has to be considered as well. For better understanding the individual contributions, the model scattering curves corresponding to the individual contributions are shown in Fig. 4.

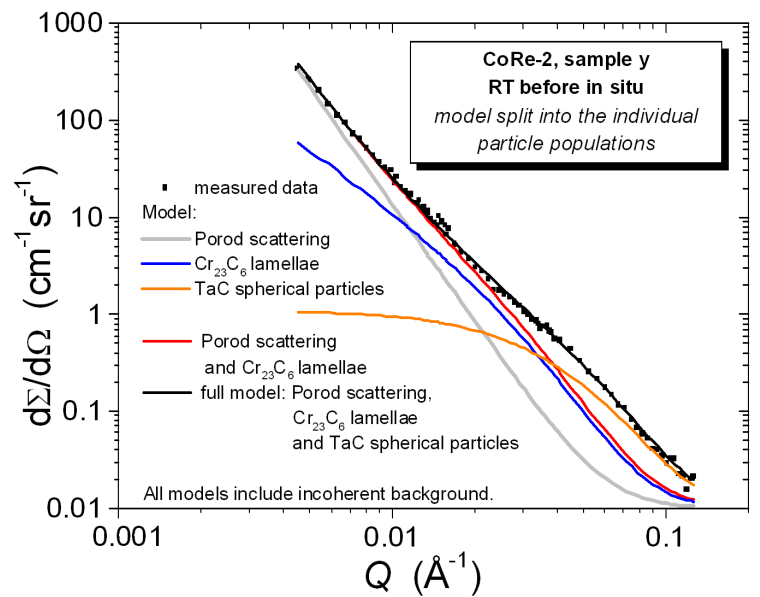

Fig. 4. Model split of the scattering contributions from the individual particle populations.

For samples held for $4 \mathrm{~h}$ at all tested temperatures (Fig. 3), evolution of the scattering curves is clearly visible. It should be noted that one plate-like sample (cut from the same specimen bar) was used for one hightemperature test. For the sample denoted y (which was held at $1000^{\circ} \mathrm{C}$ ), scattering at largest $Q$-values decreases with hold time and shifts towards lower $Q$ region. Importantly, it is not possible to describe the change of the scattering curve at $1000^{\circ} \mathrm{C}$ without considering coarsening of both the fine lamellar $\mathrm{Cr}_{23} \mathrm{C}_{6}$ carbides as well as the globular TaC precipitates. The coarsening is even more pronounced when the temperature of hold is $1100^{\circ} \mathrm{C}$ (sample denoted $\mathrm{v}$ ).

At and above $1200^{\circ} \mathrm{C}$, the scattering after $4 \mathrm{~h}$ hold fulfills the Porod law in the measured $Q$-range (additionally, flat incoherent scattering background has to be also taken into account for $Q$ values $>0.03 \AA^{-1}$ ). Therefore, it can be deduced that all the precipitate sizes exceed $1000 \AA$ and thus contribute only to the asymptotic part of the scattering.

At $1200^{\circ} \mathrm{C}$, the Porod scattering is more intense than at $1260{ }^{\circ} \mathrm{C}$ and at $1300^{\circ} \mathrm{C}$ (Fig. 3). It is in agreement with the fact that $\mathrm{Cr}_{23} \mathrm{C}_{6}$ phase dissolves above $1200{ }^{\circ} \mathrm{C}[2,4]$. At $1260{ }^{\circ} \mathrm{C}$ and $1300^{\circ} \mathrm{C}$, the only remaining large particles causing the Porod scattering are $\sigma$ phase and large $\mathrm{TaC}$, whereas large $\mathrm{Cr}_{23} \mathrm{C}_{6}$ carbides (which were still 
additionally contributing to the scattering at $1200^{\circ} \mathrm{C}$ ) are dissolved at these temperatures. The dissolution of $\mathrm{Cr}_{23} \mathrm{C}_{6}$ carbides above $1200^{\circ} \mathrm{C}$ can be also indirectly deduced from the data measured at RT after HT exposure (data not shown here due to the limited space). The strong scattering increase is observed after cooling from 1260 as well as $1300^{\circ} \mathrm{C}$ (due to re-precipitation of $\mathrm{Cr}_{23} \mathrm{C}_{6}$ lamellae), whereas no change is observed after cooling from 1000 and $1100^{\circ} \mathrm{C}$. Small increase is observed after cooling from $1200{ }^{\circ} \mathrm{C}$, which probably indicates that $\mathrm{Cr}_{23} \mathrm{C}_{6}$ carbides were partially dissolved during the $4 \mathrm{~h}$ hold at $1200{ }^{\circ} \mathrm{C}$.

There is no significant difference between the scattering intensity for $4 \mathrm{~h}$ hold at $1260^{\circ} \mathrm{C}$ and at $1300^{\circ} \mathrm{C}$. It means that no dissolution of any minority phase occurred between $1260{ }^{\circ} \mathrm{C}$ and $1300^{\circ} \mathrm{C}$ and, also, that the coarsening of the remaining large precipitates is not significantly different for these two temperatures.

TABLE

TaC fine precipitates - parameters determined by SANS.

\begin{tabular}{c|c|c|c|c}
\hline \hline $\begin{array}{c}\text { CoRe-2 } \\
\text { sample }\end{array}$ & $\begin{array}{c}T \\
{\left[{ }^{\circ} \mathrm{C}\right]}\end{array}$ & $\begin{array}{c}\text { hold } \\
\text { time }[\mathrm{h}]\end{array}$ & $\begin{array}{c}\text { mean } \\
\text { diam. }[\AA]\end{array}$ & $\begin{array}{c}\text { volume } \\
\text { frac. }[\%]\end{array}$ \\
\hline $\mathrm{y}$ & $\mathrm{RT}$ & & 76 & 0.33 \\
$\mathrm{y}$ & 1000 & 1 & 102 & 0.32 \\
$\mathrm{y}$ & 1000 & 4 & 147 & 0.33 \\
$\mathrm{v}$ & 1100 & 1 & 182 & 0.33 \\
$\mathrm{v}$ & 1100 & 4 & 560 & 0.35 \\
$\mathrm{w}$ & 1200 & 1 & 970 & 0.33 \\
$\mathrm{w}$ & 1200 & 4 & $>1000$ &
\end{tabular}

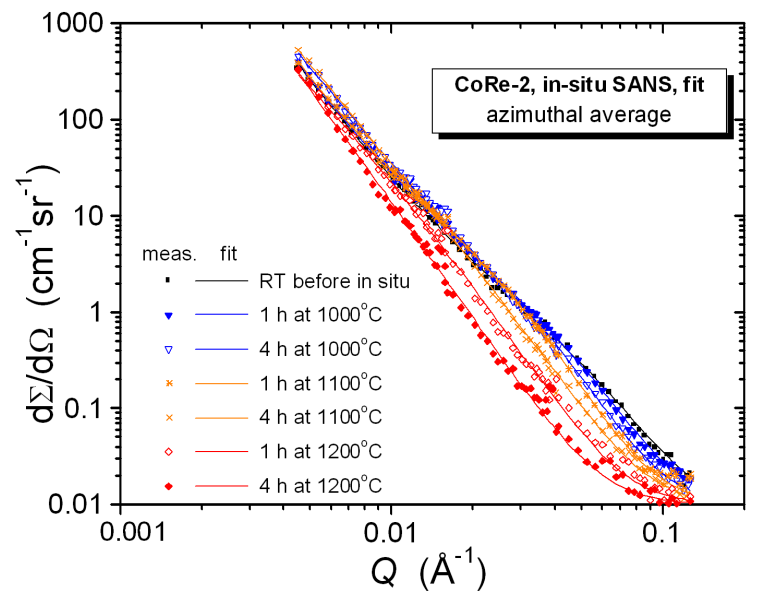

Fig. 5. The measured and fitted scattering curves at $\mathrm{RT}, 1000,1100$, and $1200{ }^{\circ} \mathrm{C}$.

The fitted scattering curves for the measurements which exhibit an additional scattering above the Porod scattering (i.e. measurements at RT, 1000 and $1100^{\circ} \mathrm{C}$ and $1 \mathrm{~h}$ hold at $1200^{\circ} \mathrm{C}$ ) are displayed in Fig. 5 . The resulting volume fractions and mean sizes (volume weighted) of fine $\mathrm{TaC}$ precipitates from these fits are summarized in the Table. The volume fraction of TaC particles was determined assuming a scattering contrast of $2.68 \times 10^{10} \mathrm{~cm}^{-2}$ for $\mathrm{TaC}$ (stoichiometric composition) in the $\mathrm{Co}-\mathrm{Re}-\mathrm{Cr}$ matrix solid solution [8].

\section{Conclusions}

Co-Re-based alloys have been extensively investigated by neutron diffraction and small-angle neutron scattering for the last few years. Stability of matrix and of the minority phases was studied.

As $\mathrm{Cr}_{23} \mathrm{C}_{6}$ carbides were found unstable at temperatures above $1000^{\circ} \mathrm{C}$, experimental Co-Re alloy containing $\mathrm{TaC}$ precipitates for strengthening at higher temperatures was introduced. Wide angle measurements showed that very large precipitates of the $\mathrm{TaC}$ phase do not dissolve up to at least $1300^{\circ} \mathrm{C}$. However, small-angle neutron scattering showed that its finer morphological variant most suitable for high temperature strengthening i.e. the fine globular $\mathrm{TaC}$ precipitates of less than $300 \AA$ size - coarsened even at relatively low temperature of $1000^{\circ} \mathrm{C}$. This coarsening is faster at higher temperatures and the mean size exceeded $1000 \AA$ at $1200^{\circ} \mathrm{C}(4 \mathrm{~h}$ hold). They are therefore not detected in the present in situ SANS measurements at temperatures of $1260{ }^{\circ} \mathrm{C}$ and $1300{ }^{\circ} \mathrm{C}$ due to the limited $Q$ range.

\section{Acknowledgments}

The authors thank PSI Villigen, Switzerland, FRMII Garching, Germany, and CANAM (NPI Rež), Czech Republic, for providing the beamtime for neutron scattering measurements and tests. P. Strunz, P. Beran, and G. Farkas acknowledge support by GACR project no. 14-36566G. The neutron diffraction measurements were supported by EC under the FP7 infrastructural project No. 283883 - NMI3-II and by CZ MSMT infrastructural project No. LM2011019. The authors would like to thank the German Research Foundation (DFG) for providing the financial support for the joint $\mathrm{Co}-\mathrm{Re}$ alloy development project at TU Braunschweig and TU Münich (RO 2045/31-1 and GI 242/4-1, respectively).

\section{References}

[1] J. Rösler, D. Mukherji, T. Baranski, Adv. Eng. Mater. 9, 876 (2007).

[2] D. Mukherji, P. Strunz, S. Piegert, R. Gilles, M. Hofmann, M. Hölzel, J. Rösler, Metall. Mater. Trans. 43A, 1834 (2012).

[3] D. Mukherji, J. Rösler, J. Wehrs, P. Strunz, P. Beran, R. Gilles, M. Hofmann, M. Hoelzel, H. Eckerlebe, L. Szentmiklosi, Z. Macsik, Metall. Mater. Trans. A 44, 22 (2013).

[4] D. Mukherji, P. Strunz, R. Gilles, M. Hofmann, F. Schmitz, J. Rösler, Mater. Lett. 64, 2608 (2010).

[5] R. Gilles, P. Strunz, D. Mukherji, M. Hofmann, M. Hoelzel, J. Roesler, J. Phys. Conf. Series 340, 012052 (2012). 
[6] D. Mukherji, M. Klauke, P. Strunz, I. Zizak, G. Schumacher, A. Wiedenmann, J. Rösler, Int. J. Mater. Res. 101, 340 (2010).

[7] T. Depka, C. Somsen, G. Eggeler, D. Mukherji, J. Rösler, M. Krüger, H. Saage Heilmaier, Mater. Sci. Eng. A 510-511, 337 (2009).

[8] D. Mukherji, R. Gilles, L. Karge, P. Strunz, P. Beran H. Eckerlebe, A. Stark, L. Szentmiklosi, Z. Mácsik, G. Schumacher, I. Zizak, M. Hofmann, M. Hoelzel, J. Rösler, J. Appl. Crystallogr. 47, 1417 (2014).

[9] G. Kostorz, in: Neutron Scattering (Treatise on Materials Science and Technology), Ed. G. Kostorz, Academic Press, New York 1979, p. 227.
[10] P. Strunz, K. Mortensen, S. Janssen, Physica B 350, e783 (2004)

[11] P. Strunz, J. Šaroun, P. Mikula, P. Lukáš, F. Eichhorn, J. Appl. Crystallogr. 30, 844 (1997).

[12] P. Strunz, J. Šaroun, U. Keiderling, A. Wiedenmann, R. Przenioslo, J. Appl. Crystallogr. 33, 829 (2000). 